\title{
Inactivation of JAK2/STAT3 Signaling Axis and Downregulation of MI mAChR Cause Cognitive Impairment in klotho Mutant Mice, a Genetic Model of Aging
}

\author{
Seok-Joo Park',2,I1, Eun-Joo Shin',1 ', Sun Seek Min*,3, Jihua An ${ }^{3}$, Zhengyi Li', Yoon Hee Chung ${ }^{4}$, \\ Ji Hoon Jeong ${ }^{5}$, Jae-Hyung Bach', Seung-Yeol $\mathrm{Nah}^{6}$, Won-Ki Kim ${ }^{7}$, Choon-Gon Jang ${ }^{8}$, Yong-Sun Kim ${ }^{2}$, \\ Yo-ichi Nabeshima9, Toshitaka Nabeshima ${ }^{10}$ and Hyoung-Chun Kim*,' \\ 'Neuropsychopharmacology and Toxicology Program, Department of Pharmacy, College of Pharmacy, Kangwon National University, Chunchon, \\ South Korea; ${ }^{2}$ llsong Institute of Life Science, Hallym University, Anyang, South Korea; ${ }^{3}$ Department of Physiology and Biophysics, College of \\ Medicine, Eulji University, Daejeon, South Korea; ${ }^{4}$ Department of Anatomy, College of Medicine, Chung-Ang University, Seoul, South Korea; \\ ${ }^{5}$ Department of Pharmacology, College of Medicine, Chung-Ang University, Seoul, South Korea; ${ }^{6}$ Ginsentology Research Laboratory, Department \\ of Physiology, College of Veterinary Medicine and Bio/Molecular Informatics Center, Konkuk University, Seoul, South Korea; ${ }^{7}$ Department of \\ Neuroscience, College of Medicine, Korea University, Seoul, South Korea; ${ }^{8}$ Department of Pharmacology, School of Pharmacy, Sungkyunkwan \\ University, Suwon, South Korea; ${ }^{2}$ Laboratory of Molecular Life Science, Institute of Biomedical Research and Innovation, Foundation for Biomedical \\ Research and Innovation, Kobe, Japan; ${ }^{10}$ Department of Regional Pharmaceutical Care and Science, Graduate School of Pharmaceutical \\ Sciences, Meijo University, Nagoya, Japan
}

We previously reported cognitive dysfunction in klotho mutant mice. In the present study, we further examined novel mechanisms involved in cognitive impairment in these mice. Significantly decreased janus kinase 2 (JAK2) and signal transducer and activator of transcription3 (STAT3) phosphorylation were observed in the hippocampus of klotho mutant mice. A selective decrease in protein expression and binding density of the $\mathrm{MI}$ muscarinic cholinergic receptor (MI mAChR) was observed in these mice. Cholinergic parameters (ie, acetylcholine (ACh), choline acetyltransferase (ChAT), and acetylcholinesterase (AChE)) and NMDAR-dependent longterm potentiation (LTP) were significantly impaired in klotho mutant mice. McN-A-343 (McN), an MI mAChR agonist, significantly attenuated these impairments. AG490 (AG), a JAK2 inhibitor, counteracted the attenuating effects of McN, although AG did not significantly alter the $\mathrm{McN}$-induced effect on AChE. Furthermore, AG significantly inhibited the attenuating effects of $\mathrm{McN}$ on decreased NMDAR-dependent LTP, protein kinase C $\beta \|$, $\mathrm{p}$-ERK, $\mathrm{p}-\mathrm{CREB}, \mathrm{BDNF}$, and $\mathrm{p}$-JAK2/p-STAT3-expression in klotho mutant mice. In addition, k252a, a BDNF receptor tyrosine kinase B (TrkB) inhibitor, significantly counteracted McN effects on decreased ChAT, ACh, and $\mathrm{MI}$ mAChR and p-JAK2/p-STAT3 expression. McN-induced effects on cognitive impairment in klotho mutant mice were consistently counteracted by either AG or k252a. Our results suggest that inactivation of the JAK2/STAT3 signaling axis and MI mAChR downregulation play a critical role in cognitive impairment observed in klotho mutant mice.

Neuropsychopharmacology (2013) 38, I426-|437; doi: I0.1038/npp.2013.39; published online 27 February 2013

Keywords: cognitive impairment; JAK2/STAT3; klotho gene; long-term potentiation; MI mAChR; PKC/ERK/CREB/BDNF

\section{INTRODUCTION}

Klotho mutant mice, which harbor a defective klotho gene, have an extremely short lifespan (around 8 weeks).

*Correspondence: Dr H-C Kim, Neuropsychopharmacology and Toxicology Program, Department of Pharmacy, College of Pharmacy, Kangwon National University, Chunchon 200-70I, South Korea, Tel: +82 33250 6917, Fax: + 8233255 7865, E-mail: kimhc@kangwon.ac.kr or Dr SS Min, Department of Physiology and Biophysics, College of Medicine, Eulji University, Daejeon 301-746, South Korea, Tel: + 8242259 1633, Fax: + 8242259 1639, E-mail: ssmin@eulji.ac.kr ${ }^{1}$ 'These two authors contributed equally to this work.

Received 19 September 2012; revised 3 January 2013; accepted 28 January 2013; accepted article preview online 6 February 2013
At 4-5 weeks of age, the mice develop multiple age-related syndromes, such as arteriosclerosis, osteoporosis, skin atrophy, infertility, thymic atrophy, and pulmonary emphysema (Kuro-o et al, 1997). Further evidence suggests that the klotho gene is responsible for aging. Introduction of a normal klotho gene into these mutant mice improves their phenotypes (Kuro-o et al, 1997), and overexpression of this gene in normal wild-type mice significantly extends their life spans (Kurosu et al, 2005). Although klotho mutant mice are considered to be a novel animal model for accelerated human aging, these mice do not express certain phenotypes usually seen in aged humans, such as brain atrophy with amyloid or senile plaque deposition (Kuro-o et al, 1997; Nagai et al, 2003). 
Our group was the first to observe cognitive impairment in klotho mutant mice (Nagai et al, 2003). We showed that anti-death genes/proteins, Bcl-2 and Bcl-xL, are downregulated while the pro-death molecule, Bax, is upregulated in the hippocampus of klotho mutant mice (Nagai et al, 2003). In addition, Li et al (2004) demonstrated that synaptic structures and synaptophysin are reduced in number and expression, respectively, in the CA3 region of klotho mutant mice. However, very limited information is available regarding underlying mechanisms involved in significant cognitive function impairment in klotho mutant mice, although it is recognized that the klotho gene may be essential for maintaining cognitive function in aging organisms.

Earlier studies suggested that soluble signaling molecules (ie, cytokines and growth factors) and their receptors are expressed in both the developing and mature mammalian CNS (Mehler and Kessler, 1997). One intracellular signaling pathway activated by soluble signaling molecules involves two families of molecules: janus kinase (JAK) proteins and the signal transducer and activator of transcription (STAT) proteins (Ihle et al, 1995). Importantly, p-STAT3 immunoreactivity in hippocampal neurons of young subjects is substantially higher than that of older, cognitively normal humans and rodents (Chiba et al, 2009).

Because $\mathrm{McN}-\mathrm{A}-343(\mathrm{McN})$, a M1 agonist appeared to be more effective than either AF102B (AF; Fisher et al, 2003) or talsaclidine (TC; Walland and Pieper, 1998) in improving cognitive impairment in klotho mutant mice (Supplementary Figure S3), we applied McN in the present study. JAK2 is an upstream regulator of STAT3 activation. As inhibition of JAK2 activity by AG490 (AG) results in decreased STAT3 phosphorylation, we applied AG in the present study to inhibit the JAK2/STAT3 signaling axis (Chiba et al, 2009).

In the present study, we investigated whether klotho gene deficiency affects the p-JAK2/STAT3 signaling axis, and also examined whether klotho gene deficiency alters the cholinergic neuronal system. To this aim, we examined the neurochemical, electrophysiological, and behavioral parameters accompanied by aging in klotho mutant mice. We propose here that inactivation of the JAK2/STAT3 signaling axis and M1 mAChR downregulation lead to cognitive impairments in klotho mutant mice.

\section{MATERIALS AND METHODS}

\section{Animals}

All animals were treated in accordance with the National Institutes of Health (NIH) Guide for the Humane Care and Use of Laboratory Animals (NIH Publication No. 85-23, 1985; www.dels.nas.edu/ila). The present study was performed in accordance with the Institute for Laboratory Research (ILAR) guidelines for the care and use of laboratory animals. Mice were maintained under a 12-h light:12-h dark cycle and fed ad libitum. Since klotho mutant mice are infertile, wild-type and klotho mutant mice were generated by crossing heterozygous klotho mutant mice (Kuro-o et al, 1997; Nagai et al, 2003). The mice were screened by polymerase chain reaction (PCR) analysis using
DNA extracted from tail specimens. More details on the gene characterization were described in the supporting information.

\section{Guide Cannula Implantation and Intracerebroventricular Infusion}

Forty-day-old mice were anesthetized with pentobarbital (40 mg/kg, i.p.) and a stainless steel guide cannula (AG-4; Eicom, Kyoto, Japan) was implanted into the right lateral ventricle (stereotaxic coordinates: $0.5 \mathrm{~mm}$ posterior to bregma, $1 \mathrm{~mm}$ right to the midline, and $2 \mathrm{~mm}$ ventral to the dura, according to the atlas of Franklin and Paxinos, 2008 and Shin et al, 2009). Microinfusion into the lateral ventricle was performed at a rate of $1 \mu \mathrm{l} / \mathrm{min}$. More details on the guide cannula implantation and intracerebroventricular (i.c.v.) infusion were described in the supporting information.

\section{Drug Treatment and Animal Handling}

Drug treatment started after 2 days of recovery from guide cannula implantation. Because we observed, in an earlier study (Nagai et al, 2003), that cognitive impairment did not occur in klotho mutant mice until 6 weeks of age, mice received $\mathrm{McN}-\mathrm{A}-343(\mathrm{McN}, \mathrm{M} 1, \mathrm{mAChR}$ agonist; Tocris Bioscience, Ellisville, MO, USA; $1.0 \mu \mathrm{g} / \mu \mathrm{l}$ in saline, i.c.v.) on postnatal day (PND) 42, 46, 49, and 53. AG490 (JAK2/ STAT3 inhibitor; Tocris Bioscience; $15 \mathrm{mg} / \mathrm{kg} / 2 \mathrm{ml}$, i.p.) or $\mathrm{k} 252 \mathrm{a}$ (TrkB inhibitor; Tocris Bioscience; $0.3 \mathrm{mg} / \mathrm{kg} / 2 \mathrm{ml}$, i.p.) was injected $1 \mathrm{~h}$ after each $\mathrm{McN}$ treatment. Novel object recognition tests or conditioned-fear learning tests were conducted on PND 54 and 55 (Supplementary Figure S1). The dose of each drug used in this study was selected based on previous studies (Chiba et al, 2009; Liu et al, 2005; Wall et al, 2001) and our preliminary study (Bach et al, 2010). Mice were killed $30 \mathrm{~min}$ after the test trial for western blot analyses (p-JAK2, p-STAT3, mAChRs, nAChRs, and BDNF), autoradiography, neurochemical measurements, and electrophysiological analyses. To evaluate p-ERK and p-CREB expression, mice were killed $30 \mathrm{~min}$ after the training trial. Mouse body weight was recorded on a daily basis from PND 35 to 55 (Supplementary Figure S5). More details on the preparation of each reagent were described in the supporting information.

\section{Novel Object Recognition Test and Conditioned-Fear Learning Test}

Novel object recognition test and conditioned-fear learning test were performed with a slight modification as described previously (Jin et al, 2009; Nagai et al, 2003). Detailed procedure is described in the supporting information.

\section{Western Blot Analysis and Immunoprecipitation Assay}

Western blot analysis and immunoprecipitation assay were done as described previously (Jin et al, 2009). More details on the procedure and antibody were described in the supporting information. 


\section{Autoradiography}

Autoradiograms were generated and analyzed with a slight modification as described previously (Jin et al, 2009; Zhang and Buccafusco, 2000). More details on the autoradiography were described in the supporting information.

\section{Level of ACh and Activities of AChE and ChAT}

Hippocampi were homogenated in ice-cold $20 \mathrm{mM}$ sodium phosphate buffer ( $\mathrm{pH}$ 7.4). These were centrifuged at $12000 \mathrm{~g}$ for $30 \mathrm{~min}$, at $4{ }^{\circ} \mathrm{C}$. The supernatant was assayed for ACh levels using Amplex Red Acetylcholine/Acetylcholinesterase (AChE) Assay Kit (A-12217) (Eugene, Oregon, USA), according to the manufacturer's instruction. Detailed procedure was described in the supporting information. AChE activity was measured using Amplex Red Acetylcholine/ AChE Assay Kit (A-12217) (Eugene, Oregon, USA), according to the manufacturer's instruction. For choline acetyltransferase (ChAT) activity, $5 \%$ tissue homogenates were prepared in ice-cold $20 \mathrm{mM}$ sodium phosphate buffer ( $\mathrm{pH}$ 7.4), and kept frozen overnight at $-20^{\circ} \mathrm{C}$. These were thawed the following day and centrifuged at $12000 \mathrm{~g}$ for $1 \mathrm{~h}$, at $4{ }^{\circ} \mathrm{C}$. The supernatant was assayed for ChAT activity according to the method of Chao and Wolfgram (1972). Detailed procedure was described in the supporting information.

\section{Electrophysiological Recordings}

Transverse hippocampal slices were prepared from wildtype or klotho mutant mice, according to the previous report with a minor modification (Min et al, 2009). CA1 field potentials (FPs) were evoked by stimulating Schaffer collaterals with $0.2 \mathrm{~ms}$ pulses delivered through concentric bipolar stimulating electrodes (FHC, Bowdoinham, ME, USA), and recorded extracellularly in CA1 stratum radiatum. Responses were quantified as the initial FP slope in CA1. Baseline responses were recorded using half maximal stimulation intensity at $0.033 \mathrm{~Hz}$. Long-term potentiation (LTP) was examined using a conventional stimulation paradigm: four episodes of theta burst stimulation (TBS) consisting of eight bursts of four $100 \mathrm{~Hz}$ pulses were administered every $200 \mathrm{~ms}$. Because four TBS episodes induced robust LTP that lasted for $>60 \mathrm{~min}$, we measured the magnitude of NMDAR-dependent LTP induced by one TBS episode. More details on the hippocampal slice preparation were described in the supporting information.

\section{Statistical Analyses}

Data were analyzed using IBM SPSS version 19.0 (IBM, Chicago, IL, USA). One-way ANOVA was applied for the two data groups (Figure 1a and b). Three-way ANOVA was performed for the effect of klotho gene mutation, $\mathrm{McN}$, and AG490 (or k252a) (Figures 1c and d, 2, 3, and 5). The effect of k252a on the McN-mediated pharmacological actions in the klotho mutant mice was analyzed by two-way ANOVA, with $\mathrm{McN}$ and k252a as between-subjects factors (Figure 4). The statistical values are presented in Supplementary Tables S1-S4. After analysis by two- or three-way ANOVA, posthoc multiple pairwise comparisons with Bonferroni's correction were then performed. $P$-values of $<0.05$ were considered statistically significant.

\section{RESULTS}

\section{p-JAK2 and p-STAT3 Expression Was Significantly Decreased in the Hippocampus of klotho Mutant Mice}

Our experimental protocol is shown in Supplementary Figure S1. First, we investigated whether klotho gene deficiency affected p-JAK2/p-STAT3 expression, since p-JAK2/p-STAT3 decreases in an age-dependent manner (De-Fraja et al, 1998). p-JAK2 and p-STAT expression were significantly decreased (p-JAK2, $P=0.00257$; p-STAT3, $P=0.000779$ ) in klotho mutant mice (Figure 1a; Supplementary Table S1).

\section{M1 mAChR Expression Was Significantly Decreased in the Hippocampus of klotho Mutant Mice}

Next, we investigated whether $\mathrm{mAChR}$ expression was decreased in klotho-deficient mice, as M1 mAChR is downstream of the p-JAK2/p-STAT3 signaling axis (Chiba et al, 2009).

Of the five muscarinic acetylcholine receptors (M1-M5 mAChRs) examined, only M1 mAChR expression was significantly decreased $(P=0.00464)$ in klotho mutant mice. Conversely, nicotinic acetylcholine receptor subtypes $(\alpha 4$ $\mathrm{nAChR}, \alpha 7 \mathrm{nAChR}, \beta 2 \mathrm{nAChR}$, or $\alpha 4 \beta 2 \mathrm{nAChR}$ ) were not significantly different in the mutant mice (Figure $1 \mathrm{~b}$; Supplementary Table S1).

\section{AG490 Antagonism Against McN-Induced Effects on Reduced M1 mAChR Expression and $\left[{ }^{3} \mathrm{H}\right]$-Pirenzepine- Binding Density in the Hippocampus of klotho Mutant Mice}

Since M1 mAChR expression and p-JAK2/p-STAT3 signaling is decreased in animal models of Alzheimer's disease (Chiba et al, 2009), we examined whether $\mathrm{McN}$, a specific M1 mAChR agonist, affected M1 mAChR expression or $\left[{ }^{3} \mathrm{H}\right]$-pirenzepine-binding density in the hippocampus of klotho mutant mice. In addition, we investigated whether AG, an inhibitor of JAK2/STAT3 signaling, affected McNinduced changes.

Three-way ANOVA indicated significant effects of klotho gene mutation, $\mathrm{McN}$ and AG490, and a significant interaction between klotho gene mutation and $\mathrm{McN}$ (Supplementary Table S1). A post-hoc test revealed that McN treatment significantly attenuates $(P=0.00308)$ the reduction in M1 mAChR expression in klotho mutant mice. This attenuation was significantly inhibited $(P=0.0268)$ by AG490. However, AG490 per se did not significantly alter M1 mAChR expression in either wild-type or klotho mutant mice treated with vehicle and saline (Figure 1c). Representative autoradiograms showing the distribution of $\left[{ }^{3} \mathrm{H}\right]$-pirenzepine binding are presented in Figure 1d. Three-way ANOVA showed significant effects (CA1, CA3, and dentate gyrus (DG)) of klotho gene mutation, $\mathrm{McN}$ and $\mathrm{AG} 490$, and a significant interaction between klotho gene mutation and McN (DG; Supplementary Table S1). Strong binding was noted in the CA1 region and DG, whereas mild binding was observed in the $\mathrm{CA} 2 / 3$ region in the hippocampus of wild-type mice 
a
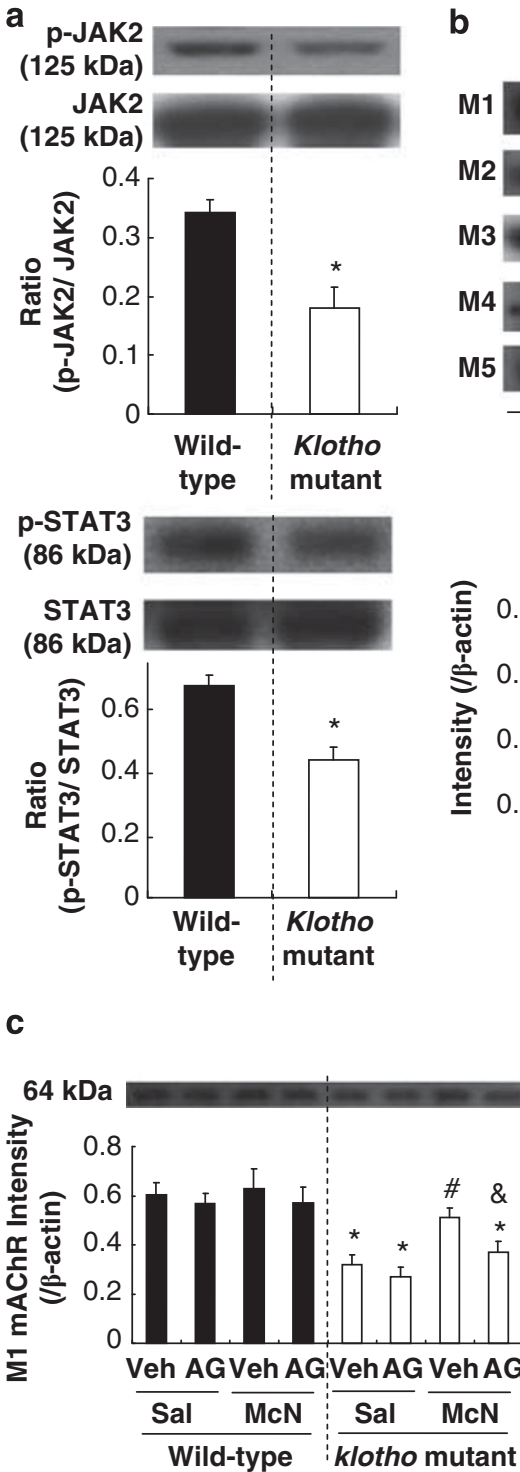

b
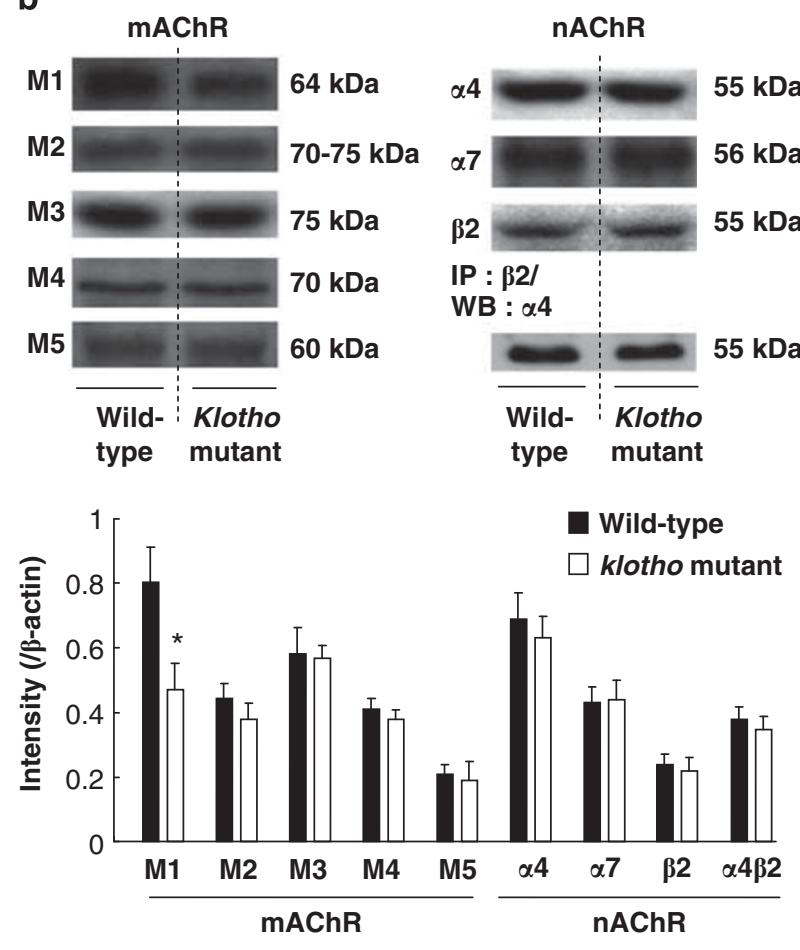

d Wild-type

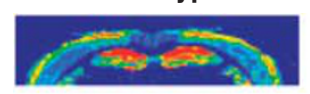

Veh + Sal

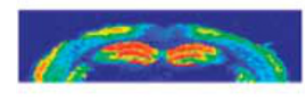

$A G+$ Sal

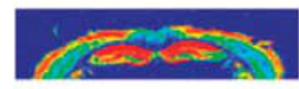

$\mathrm{Veh}+\mathrm{McN}$

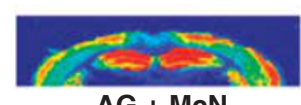

$\mathrm{AG}+\mathrm{McN}$
nAChR

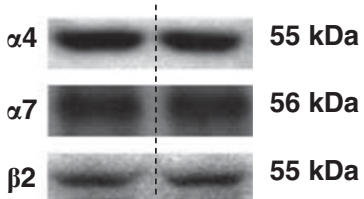

IP : $\beta 2 /$

WB : $\alpha 4$

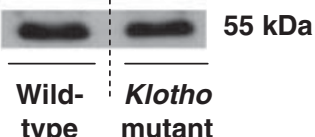

Wild- Klotho

mutant

\section{Wild-type}

klotho mutant

\author{
$k \mathrm{BDa}$ \\ 5 kDa \\ 5 kDa
}




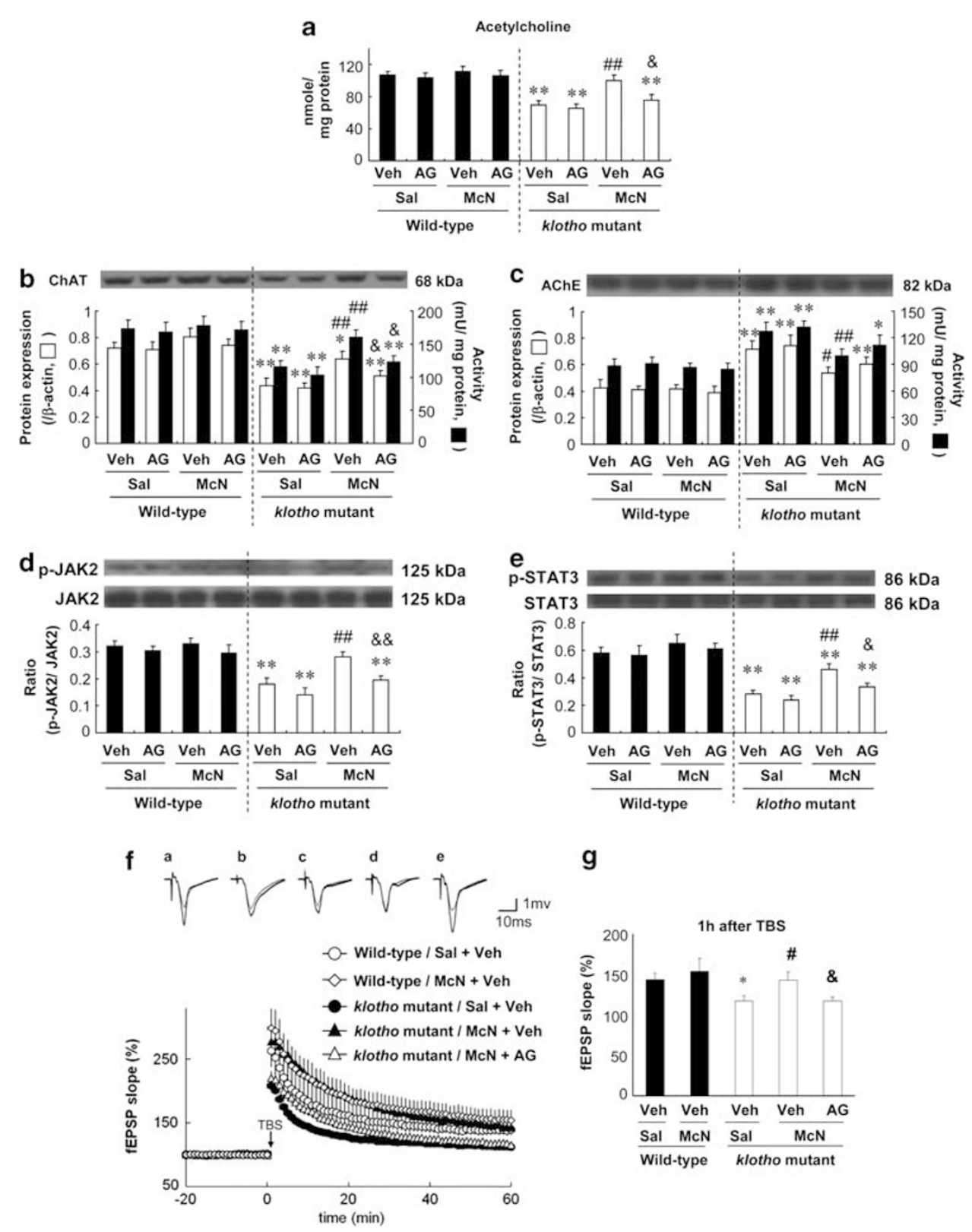

Figure 2 AG antagonism against McN-induced changes in acetylcholine level (a), and choline acetyltransferase (ChAT) protein expression (b), ChAT activity (b), AChE protein expression (c), AChE activity (c), p-JAK2 (d), p-STAT3 expression (e), and NMDAR-dependent LTP (f, g) in the hippocampus of klotho mutant mice. (f) Field EPSP slope (\% of baseline) was plotted against time. LTP was induced by application of one TBS episode. Insets: representative traces recorded before (thin line), 60 min (thick line) after one TBS episode. A: Wild-type/Sal + Veh ( $n=1$ I), B: klotho mutant/Sal + Veh ( $n=1$ I), C: klotho mutant/McN + Veh $(n=10)$, D: Klotho mutant/McN + AG490 ( $n=1 \mathrm{I})$, E: wild-type/McN + Veh $(n=8)$. (g) Comparison of average early-LTP magnitude 58-60 min after TBS application. AG490 blocked the reversal effects of McN on NMDAR-dependent LTP. Veh =Vehicle (50\% DMSO in saline, the solvent for AG490); Sal = Saline; AG = AG490 ( $15 \mathrm{mg} / \mathrm{kg} / 2 \mathrm{ml}$, i.p.); $\mathrm{McN}=\mathrm{McN}-\mathrm{A}-343(1.0 \mu \mathrm{g} / \mu \mathrm{l}$ in saline, i.c.v.). Each value is the mean $\pm \mathrm{SEM}$ of six animals (a-e) or $8-$ II animals (f, g). ${ }^{*} P<0.05,{ }^{* *} P<0.0$ I vs corresponding wild-type mice; ${ }^{\#} P<0.05,{ }^{\# \#} P<0.0$ I vs klotho mutant mice treated with Veh and Sal; ${ }^{\&} P<0.05$, ${ }_{2} \& P<0.01$ vs klotho mutant mice treated with Veh and MCN (three-way ANOVA followed by multiple pairwise comparisons with Bonferroni's correction).

hippocampus of klotho mutant mice. AG490 significantly counteracted (CA1, $P=0.0209 ; \mathrm{CA} 2 / 3, \quad P=0.0416 ; \quad \mathrm{DG}$, $P=0.00960) \mathrm{McN}$ effects (Figure 1d).

\section{AG490 Antagonism Against McN-Induced Effects on Altered Cholinergic System and p-JAK2/p-STAT3 in klotho Mutant Mice}

Since earlier reports demonstrated that M1 mAChR agonists reverse cholinergic impairment (Calabresi et al, 1998; Fisher et al, 2003; Walland et al, 1998), we next investigated whether $\mathrm{McN}$ attenuated changes in klotho mutant mice cholinergic parameters. We subsequently examined whether AG affected McN pharmacological effects. Three-way ANOVA showed significant effects of klotho gene mutation (ACh, ChAT expression ChAT activity, AChE expression, and $\mathrm{AChE}$ activity), $\mathrm{McN}$ (ACh, ChAT expression ChAT activity, AChE expression, and AChE activity), and AG490 (ACh, ChAT expression, and ChAT activity), and a significant interaction between klotho gene mutation and 
McN (ACh, AChE expression, and AChE activity; Supplementary Table S2). A post-hoc test indicated that acetylcholine ACh level $\left(P=4.24 \times 10^{-5}\right)$, ChAT protein

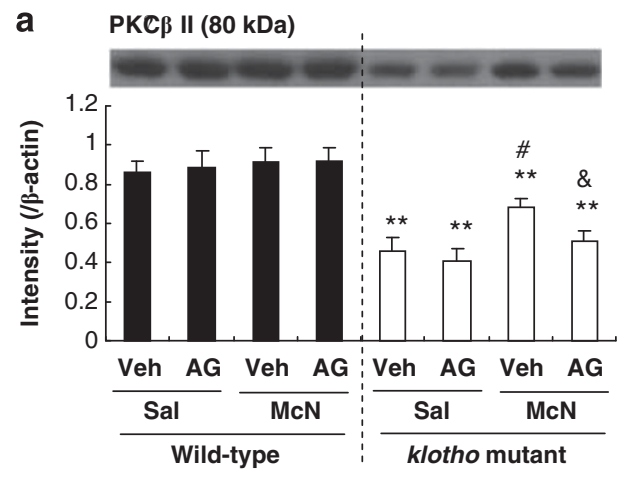

b p-ERK $(42 / 44 \mathrm{kDa})$

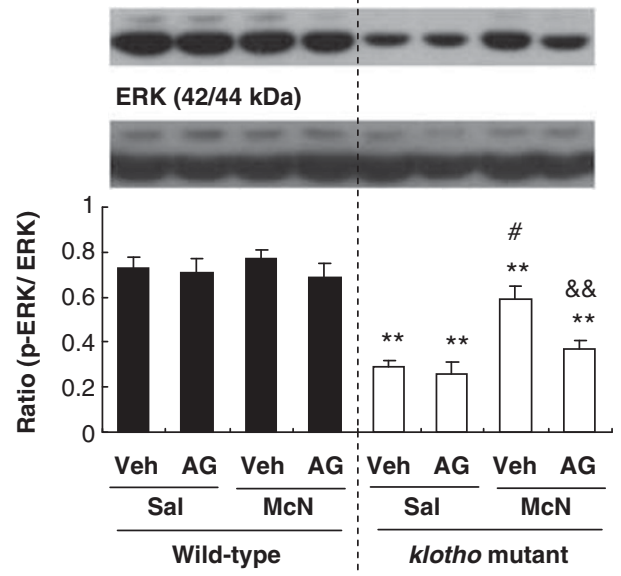

C $\mathrm{p}$-CREB $(43 \mathrm{kDa})$
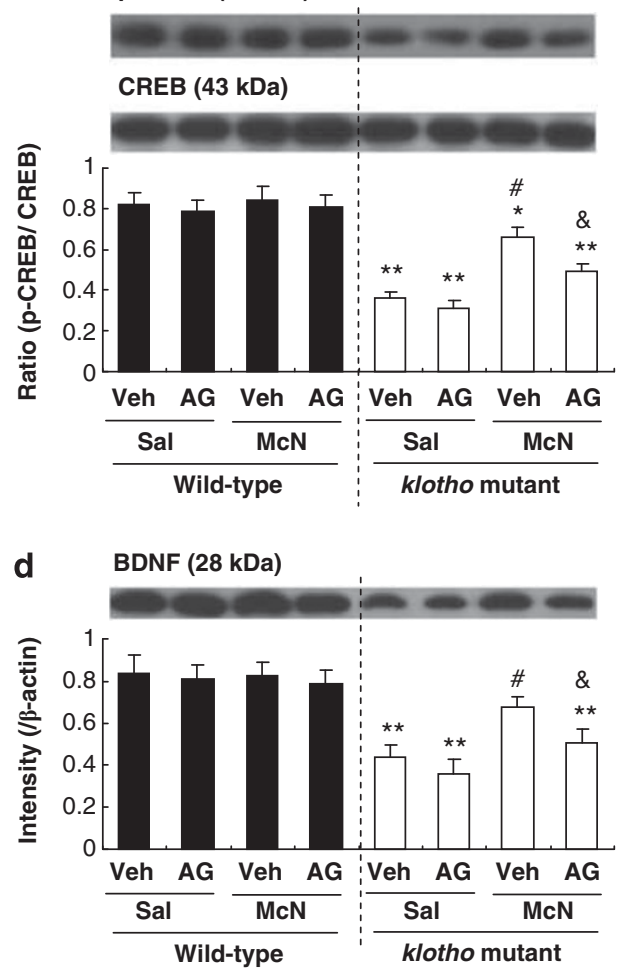

expression $\left(P=5.15 \times 10^{-5}\right)$, and ChAT activity $(P=8.59$ $\times 10^{-4}$ ) were significantly decreased in the hippocampus of klotho mutant mice (Figure $2 \mathrm{a}$ and $\mathrm{b}$ ). In contrast, AChE protein expression $\left(P=2.15 \times 10^{-4}\right)$ and AChE activity $\left(P=6.38 \times 10^{-4}\right)$ were significantly increased in klotho mutant mice (Figure $2 \mathrm{c}$ ). $\mathrm{McN}$ treatment significantly attenuated (ACh level, $P=7.38 \times 10^{-4}$; ChAT expression, $P=9.87 \times 10^{-4}$; ChAT activity, $P=0.00673$; AChE expression, $P=0.0160$; AChE activity, $P=0.00998)$ these alterations in klotho mutant mice. AG treatment significantly inhibited $\mathrm{McN}$-induced effects on decreased ACh level $(P=0.0182)$, ChAT expression $(P=0.0187)$, and its activity $(P=0.0200)$. However, AG failed to significantly inhibit $\mathrm{McN}$-induced effects on increased AChE expression and its activity in klotho mutant mice (Figure $2 \mathrm{a}-\mathrm{c}$ ).

Although there is no existing evidence that an $\mathrm{M} 1 \mathrm{mAChR}$ agonist per se increases p-JAK2/STAT3 signaling in an animal model of aging or neurodegeneration, IL-6, a STAT3 activator, increases carbachol-induced p-ERK (Chiba et al, 2009). Additionally, carbachol plays a role as a mAChR agonist via the M1 type mAChR (Anagnostaras et al, 2003). Therefore, we examined whether $\mathrm{McN}$ altered p-JAK2/ STAT3 signaling in the hippocampus of klotho mutant mice. We then investigated whether AG affected pharmacological effects of $\mathrm{McN}$. Three-way ANOVA revealed significant effects of klotho gene mutation, McN and AG490 on p-JAK2 and p-STAT3 expression. In addition, a significant interaction between klotho gene mutation and $\mathrm{McN}$ was shown in the p-JAK2 expression (Supplementary Table S2). A posthoc test indicated that $\mathrm{McN}$ significantly attenuated reduced p-JAK2 $(P=0.00191)$ and p-STAT3 $(P=0.00234)$ expression in klotho mutant mice, although $\mathrm{McN}$ treatment did not significantly alter p-JAK2 or p-STAT3 expression in wild-type mice. Additionally, AG significantly inhibited $\mathrm{McN}$-induced effects on reduced $\mathrm{p}-\mathrm{JAK} 2$ and $\mathrm{p}$-STAT3 in klotho mutant mice (p-JAK2, $P=0.00837$; p-STAT3, $P=0.0236)$. However, AG490 per se did not significantly affect p-JAK2 and p-STAT3 expression in either wild-type or klotho mutant mice (Figure $2 \mathrm{~d}$ and e).

\section{AG490 Antagonism Against McN-Induced Effects on Impaired NMDAR-Dependent LTP in klotho Mutant Mice}

After behavioral testing, we measured LTP magnitude in the CA1 area of hippocampal slices prepared from klotho mutant or wild-type mice using a maximal LTP protocol (Supplementary Figure S2; Figure 2f and g). We tested whether the reduced cholinergic activity in klotho mutant mice was a possible reason for impaired LTP induction with the use of $\mathrm{McN}$. McN treatment significantly reversed the LTP impairment in klotho mutant mice (Figure $2 \mathrm{f}$ and $\mathrm{g}$ ).

\footnotetext{
Figure 3 AG490 antagonism against McN-induced effects on PKC $\beta \|$ (a), p-ERK (b), p-CREB (c), and BDNF (d) expression in the hippocampus of klotho mutant mice. Veh $=$ Vehicle (50\% DMSO in saline, the solvent for AG490); Sal = Saline; $A G=A G 490$ ( $15 \mathrm{mg} / \mathrm{kg} / 2 \mathrm{ml}$, i.p.); $M c N=M c N-A-$ $343(1.0 \mu \mathrm{g} / \mu \mathrm{l}$ in saline, i.c.v.). Each value is the mean \pm SEM of six animals. ${ }^{*} P<0.05,{ }^{* *} P<0.01$ vs corresponding wild-type mice; ${ }^{\#} P<0.01$ vs klotho mutant mice treated with Veh and Sal; ${ }^{\&} P<0.05,{ }^{\&} \& P<0.01$ vs klotho mutant mice treated with Veh and McN (three-way ANOVA followed by multiple pairwise comparisons with Bonferroni's correction).
} 
a
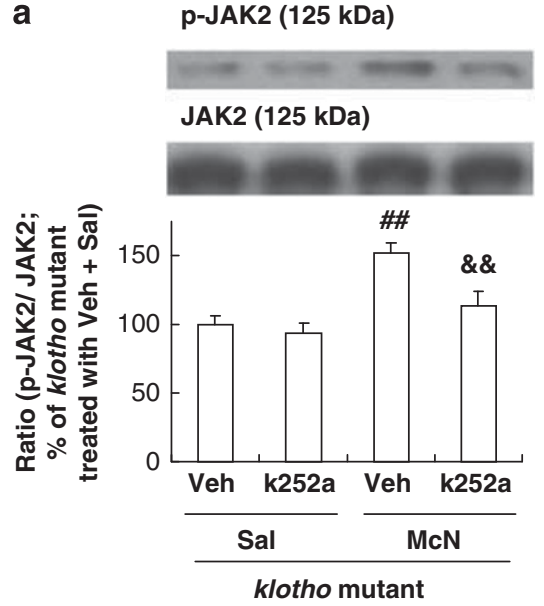

C ChAT (68 kDa)

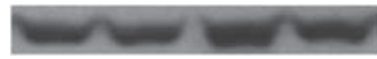

Protein expression (/ $\beta$-actin)

Activity (mU/ mg protein)

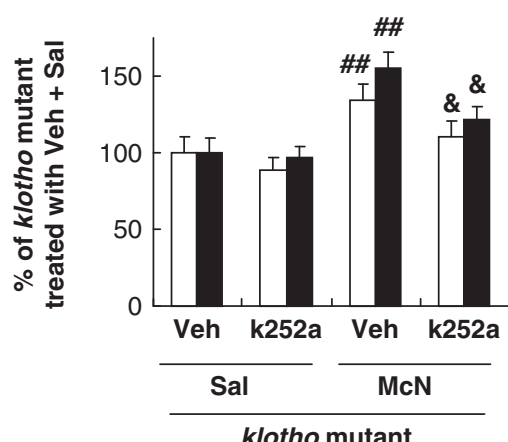

e

Acetylcholine

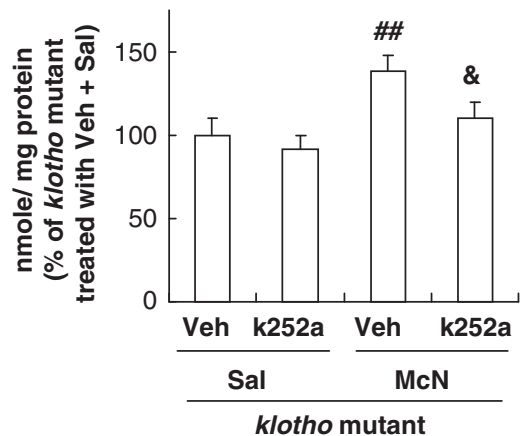

b

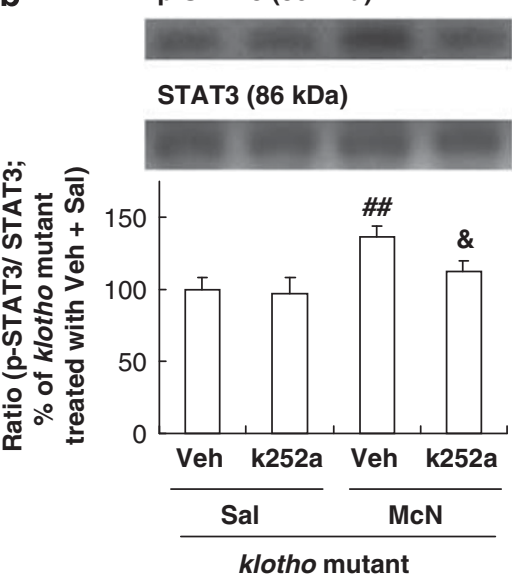

d AChE (82 kDa)

Protein expression (/ $\beta$-actin)

Activity (mU/ mg protein)

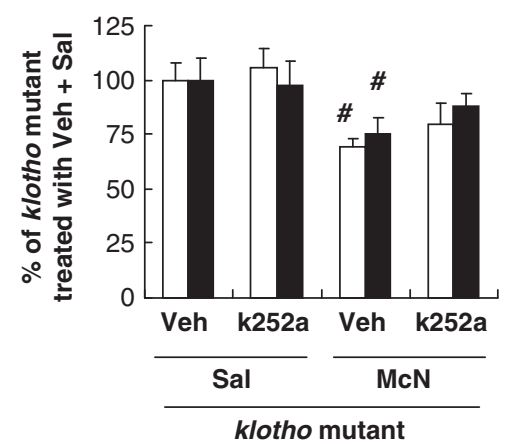

f

M1 mAChR (64 kDa)

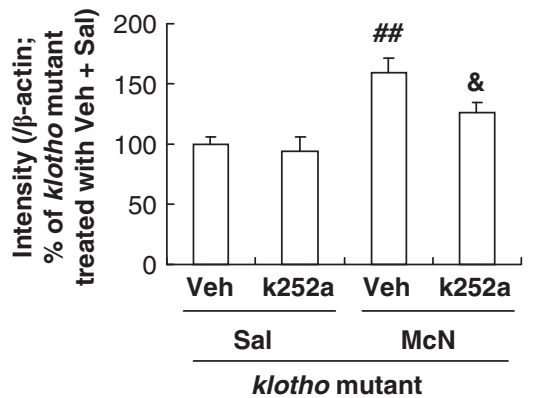

Figure 4 K252a antagonism against McN-induced effects on p-JAK2 (a), p-STAT3 (b), choline acetyltransferase (c), AChE (d), and MI mAChR (f), and the level of acetylcholine (e) in the hippocampus of klotho mutant mice. Veh=Vehicle (5\% DMSO in saline, the solvent for k252a); Sal = Saline; $k 252 a=k 252 a$ $\left(0.3 \mathrm{mg} / \mathrm{kg} / 2 \mathrm{ml}\right.$, i.p.); $\mathrm{McN}=\mathrm{McN}-\mathrm{A}-343\left(\mathrm{I} .0 \mu \mathrm{g} / \mu \mathrm{l}\right.$ in saline, i.c.v.). Each value is the mean \pm SEM of six animals. ${ }^{\#} P<0.05$, ${ }^{\# \#} P<0.01$ vs $\mathrm{klotho}$ mutant mice treated with Veh and Sal; ${ }^{\&} P<0.05,{ }^{\& \&} P<0.01$ vs klotho mutant mice treated with Veh and McN (two-way ANOVA followed by multiple pairwise comparisons with Bonferroni's correction).

Three-way ANOVA showed significant effects of klotho gene mutation and AG490 (Supplementary Table S2). The magnitude of NMDAR-dependent LTP in slices from klotho mutant mice treated with $\mathrm{McN}$ was $142.38 \pm 10.04 \%$ of baseline $(n=10) \quad 1 \mathrm{~h}$ after TBS application. These values were higher than those in slices from klotho mutant mice treated with vehicle $(116.80 \pm 6.59 \%$ of baseline, $1 \mathrm{~h}$ after TBS application, $P=0.0389$; Figure $2 \mathrm{~g}$ ). Although the magnitude of NMDAR-dependent LTP in slices from wild-type mice treated with $\mathrm{McN}$ alone was slightly higher than in slices from control mice treated with vehicle, the two groups were not significantly different ( $154.13 \pm 15.84 \%$ vs $143.82 \pm 7.71 \%$ of baseline, respectively, $P=0.434)$. 
a

Novel object recognition test
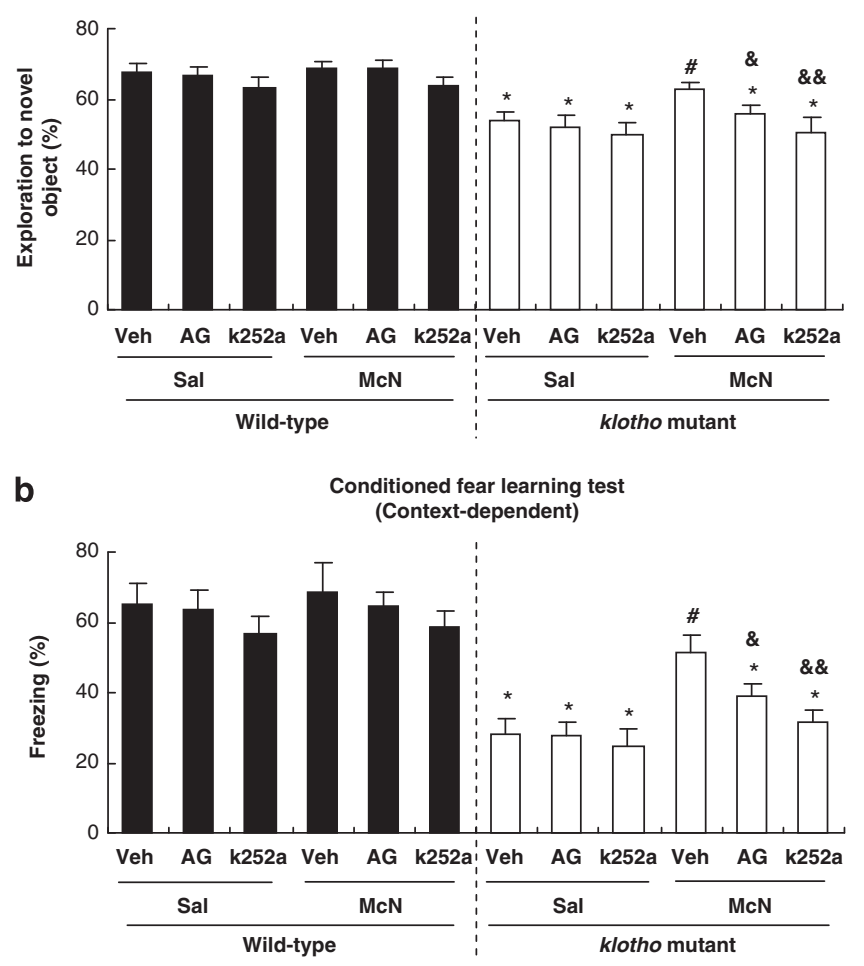

Figure 5 Antagonism by AG490 or k252a against McN-induced effects on novel object recognition (a) and conditioned-fear learning performance (b) of klotho mutant mice. Veh = Vehicle (50\% DMSO in saline, the solvent for AG490); Sal = Saline; AG = AG490 ( $15 \mathrm{mg} / \mathrm{kg} / 2 \mathrm{ml}$, i.p.); $k 252 \mathrm{a}=\mathrm{k} 252 \mathrm{a}$ $(0.3 \mathrm{mg} / \mathrm{kg} / 2 \mathrm{ml}$, i.p.); $\mathrm{McN}=\mathrm{McN}-\mathrm{A}-343(\mathrm{I} .0 \mu \mathrm{g} / \mu \mathrm{l}$ in saline, i.c.v.). Neither $50 \%$ DMSO nor 5\% DMSO solution affect significantly memory performance; thus, shown as Veh for AG490. Each value is the mean \pm SEM of I 5 animals. ${ }^{*} P<0.0$ I vs corresponding wild-type mice; ${ }^{\#} P<0.0$ I vs klotho mutant mice treated with Veh and $\mathrm{Sal} ;{ }^{\&} P<0.05,{ }^{\&} \& P<0.01$ vs klotho mutant mice treated with Veh and McN (three-way ANOVA followed by multiple pairwise comparisons with Bonferroni's correction).

We then investigated whether the M1 agonist required JAK2/STAT3 signaling to attenuate the NMDAR-dependent LTP impairment. In the presence of AG490, the $\mathrm{McN}$ effect on LTP induction was not reversed; the average LTP magnitude in slices from klotho mutant mice treated with $\mathrm{McN}$ and $\mathrm{AG} 490$ was $117.08 \pm 4.60$, significantly lower than that in slices from klotho mutant mice treated with MCN or vehicle $(142.38 \pm 10.04 \%$ of baseline; $P=0.0406)$. These results suggest that M1 $\mathrm{mAChR}$ and JAK2/STAT3 interaction is required to induce normal NMDAR-dependent LTP.

\section{AG490 Antagonism Against McN-Induced Effects on PKC $\beta$ II, p-ERK, p-CREB and BDNF Expression in the Hippocampus of klotho Mutant Mice}

M1 mAChR stimulation activates a G-protein belonging to the pertussis toxin-insensitive $\mathrm{Gq} / 11$ family. Gq/11 subunits stimulate phospholipase C, inducing IP3-dependent calcium release and protein kinase $C$ (PKC) activation (Fisher et al, 2003). PKC pathways are strong candidates for mediating the molecular changes that underlie spatial learning, as they play critical roles in neurotransmitter release and synaptic plasticity, and deletion of specific
PKC genes results in learning deficits. To understand the role of PKC in our experimental system, we examined PKC isozyme protein expression in the hippocampus of klotho mutant mice (Figure 3a; Supplementary Figure S4). Threeway ANOVA indicated significant effects of klotho gene mutation, $\mathrm{McN}$ and $\mathrm{AG} 490$ on $\mathrm{PKC} \beta \mathrm{II}$ expression (Supplementary Table S3), but not on $\mathrm{PKC} \alpha, \mathrm{PKC} \beta \mathrm{I}, \mathrm{PKC} \delta$, or PKC $\zeta$ expression (Supplementary Figure S4; Supplementary Table S6). Post-hoc analysis showed that PKC $\beta$ II expression was significantly and selectively decreased $\left(P=1.45 \times 10^{-6}\right)$ in klotho mutant mice (Figure 3a), whereas $\mathrm{PKC} \alpha, \mathrm{PKC} \beta \mathrm{I}, \mathrm{PKC} \delta$, and $\mathrm{PKC} \zeta$ (Supplementary Figure S4) were not significantly different from wild-type. $\mathrm{McN}$ significantly attenuated $(P=0.00215)$ the decreased PKC $\beta$ II expression in klotho mutant mice. Consistently, AG490 significantly counteracted $\mathrm{McN}-$ mediated attenuation $(P=0.0122)$.

ERK1/2 signal transduction pathways are downstream of the PKC pathway (Fisher et al, 2003) and are also involved in synaptic plasticity, learning, and memory. ERK is necessary for the development of several forms of memory, such as fear conditioning, conditioned taste aversion, spatial memory, step-down inhibitory avoidance, and object recognition memory (Alkam et al, 2010). ERK regulates CREB function and BDNF expression (Williams et al, 2008). CREB is a critical mediator of activity-induced transcriptional signaling of dendrite growth in response to neuronal activity (Wayman et al, 2006). Three-way ANOVA indicated significant effects of klotho gene mutation, McN and AG490, and a significant interaction between klotho gene mutation and $\mathrm{McN}$ on the expression of p-ERK, p-CREB, and BDNF (Supplementary Table S3). No significant change in ERK1/2 expression was observed among the groups in this study. However, a post-hoc test revealed that $\mathrm{p}$-ERK1/2 expression was significantly decreased $\left(P=5.22 \times 10^{-8}\right.$; Figure $\left.3 \mathrm{~b}\right)$ in klotho mutant mice. Similar to ERK, p-CREB and BDNF expression were significantly decreased ( $\mathrm{p}$-CREB, $P=6.02$ $\times 10^{-8}$; BDNF, $\left.P=4.00 \times 10^{-6}\right)$ in the hippocampus of klotho mutant mice (Figure $3 \mathrm{c}$ and $\mathrm{d}$ ). $\mathrm{McN}$ significantly attenuated these decreases in p-ERK $\left(P=4.26 \times 10^{-5}\right)$, p-CREB $\left(P=9.18 \times 10^{-5}\right)$, and BDNF $(P=0.00269)$ expression. Consistently, AG490 significantly reversed $\mathrm{McN}-$ mediated attenuations in klotho mutant mice (p-ERK, $P=0.00163 ; \quad p-C R E B, \quad P=0.0192 ; \quad$ BDNF, $P=0.0306$; Figure 3b-d).

\section{k252a Antagonism Against McN-Induced Effects on p-JAK2/p-STAT3, ChAT Protein Expression, ChAT Activity, AChE Protein Expression and Activity, ACh Level, and M1 mAChR Protein Expression in klotho Mutant Mice}

BDNF, a neurotrophin, activates a high-affinity cell surface receptor (TrkB) that is coupled to activation of phosphatidylinositol-3-kinase and protein kinase B (Akt). BDNF is increased in the hippocampus of rats during and after performance of a spatial learning task (a radial-arm maze), and both acquisition and maintenance of spatial memory are impaired when BDNF levels are decreased using antisense methods (Mizuno et al, 2003). BDNF specifically binds to $\operatorname{TrkB}$ receptors and induces receptor dimerization, phosphorylation, and activation of the 
intracellular tyrosine kinase domain (Mizuno et al, 2003). Therefore, we examined whether $\mathrm{McN}$-induced effects on p-JAK2 and p-STAT3 expression and cholinergic parameters (ie ChAT, AChE, Ach, and M1 mAChR) in klotho mutant mouse hippocampus were via BDNF-TrkB signaling. Two-way ANOVA indicated significant effects of McN (all parameters in Figure 4) and k252a (p-JAK2, ChAT expression and activity, ACh level, and M1 mAChR expression), and a significant interaction between $\mathrm{McN}$ and k252a (p-JAK2) (Supplementary Table S3). A post-hoc test revealed that $\mathrm{McN}$ treatment significantly increased p-JAK2 $\left(P=1.18 \times 10^{-4}\right)$, p-STAT3 $(P=0.00222)$, ChAT expression $\left(P=9.71 \times 10^{-4}\right)$, ChAT activity $(P=1.79 \times 10$

4), ACh level $(P=0.00709)$, and M1 mAChR expression $\left(P=1.97 \times 10^{-4}\right)$ in klotho mutant mice, whereas $\mathrm{McN}$ treatment significantly decreased AChE expression $(P=0.0109)$ and its enzymatic activity $(P=0.0307)$. In contrast, k252a treatment, an inhibitor of TrkB receptor tyrosine phosphorylation, resulted in significant inhibition of $\quad \mathrm{McN}$-induced $\mathrm{p}$-JAK2 $\quad(P=0.00233), \quad$ p-STAT3 $(P=0.0368), \quad$ ChAT expression $\quad(P=0.0137), \quad$ ChAT activity $(P=0.0107)$, and M1 mAChR expression $(P=0.0195)$, and ACh level $(P=0.0342)$ in klotho mutant mice. However, k252a per se did not significantly decrease AChE expression or its enzymatic activity (Figure 4).

\section{Antagonism of AG490 or k252a Against McN-Induced Effects on Cognitive Impairment in klotho Mutant Mice}

As the hippocampus is important in the formation of recognition memory in both humans and animals (ZolaMorgan et al, 1986), we evaluated visual recognition memory in a novel-object recognition memory task. The recognition test is based on the natural tendency of rodents to investigate a novel object instead of a familiar one. The choice to explore the novel object reflects the use of learning and (recognition) memory processes. Three-way ANOVA revealed significant effects of klotho gene mutation and AG490 or k252a (Supplementary Table S4). A post-hoc test indicated a significant decrease $\left(P=1.92 \times 10^{-4}\right)$ in the exploratory preference in klotho mutant mice, suggesting cognitive impairment. $\mathrm{McN}$ attenuated this decrease $(P<0.00558$; Figure 5a).

We then examined associative fear memory in a conditioned-fear task. In contextual fear conditioning, which assesses hippocampus-dependent memory, animals learn to fear the context in which they are trained to associate conditioned and unconditioned stimuli. Threeway ANOVA indicated a significant effect of klotho gene mutation, McN and AG490 or k252a, and a significant interaction between klotho gene mutation and $\mathrm{McN}$ (Supplementary Table S4). A post-hoc test revealed that contextual freezing was significantly lower in klotho mutant mice $\left(P=1.97 \times 10^{-8}\right.$ vs wild-type $)$. McN treatment significantly attenuated $\left(P=9.47 \times 10^{-5}\right)$ the lowered contextual freezing in klotho mutant mice (Figure $5 \mathrm{~b}$ ). Both AG490 and k252a treatment significantly counteracted $\mathrm{McN}$-mediated improvements in novel objective recognition (AG490, $P=0.0320 ; \mathrm{k} 252 \mathrm{a}, \quad P=6.08 \times 10^{-4}$ ) and conditioned-fear learning performance (AG490, $P=0.0443$; k252a, $P=0.00218$ ) (Figure 5).

\section{DISCUSSION}

This study revealed that klotho gene deficiency impairs hippocampal cholinergic neural systems as evidenced by significant decreases in M1 mAChR gene expression, M1 mAChR-binding density, ACh levels, ChAT activity, and ChAT gene expression, and by significant increases in AChE activity and AChE gene expression. These changes in the cholinergic neuronal system may be due to klotho gene deficiency in presynaptic cholinergic nerve terminals and postsynaptic neurons expressing $\mathrm{M} 1 \mathrm{mAChR}$ in the hippocampus. Klotho gene deficiency consistently decreased PKC $\beta \mathrm{II}, \mathrm{p}$-ERK, $\mathrm{p}-\mathrm{CREB}$ and BDNF expression, and NMDAR-dependent LTP (Supplementary Figure S6). To further understand the role of M1 mAChR in our experimental system, we examined the effects of $\mathrm{McN}$, an M1 agonist.

McN-induced M1 mAChR stimulation activates PKC $\beta \mathrm{II}$-, p-ERK-, p-CREB-, and BDNF-dependent pathways in the hippocampus of klotho mutant mice. BDNF activation leads to JAK2/STAT3 and TrkB signaling, followed by enhanced ChAT activity and ACh level, and further stimulation of M1 mAChR. Moreover, McN enhanced NMDAR-dependent LTP via JAK2/STAT3 signaling. Interestingly, the ChAT promoter contains a STAT consensus binding site (Cattaneo et al, 1999). We observed here that ChAT loss was pronounced in klotho mutant mice, similar to that observed in the aged brain (O'Neil et al, 1987). Thus, it is possible that presynaptically altered levels of ChAT and JAK2/STAT3 in klotho mutant mice are concomitant with basal hippocampal neuronal apoptosis (Nagai et al, 2003), and may contribute to both cognitive and behavioral symptoms. In contrast, although $\mathrm{McN}$ inhibited $\mathrm{AChE}$ expression and its activity, neither AG nor k252a counteracted these $\mathrm{McN}$ effects. Therefore, this phenomenon remains to be characterized.

In addition, we showed in the present study that klotho gene deficiency significantly deteriorated p-JAK2/p-STAT3 expression in hippocampal neurons, suggesting a critical interaction between the JAK2/STAT3 signaling axis and the cholinergic neurotransmitter system. This is the first evidence that JAK2/STAT3 inactivation in klotho mutant mice contributes to the pathogenesis of cholinergic dysfunction via dual mechanisms (ie, presynaptic downregulation of cholinergic genes such as ChAT and postsynaptic desensitization of M1 mAChR; refer to Supplementary Figure S6).

The decreased NMDAR-dependent LTP observed in klotho mutant mice may result from either decreased M1 $\mathrm{mAChR}$ expression or from downregulation of the machinery, such as PKC coupling to M1 mAChR, since LTP induction is impaired in M1 receptor knockout mice (Anagnostaras et al, 2003). M1 receptors are coupled to the Gq/11 family of G-proteins and activate PKC-mediated signaling cascades (Lu et al, 1999). In contrast, NMDA receptors are regulated by PKC (MacDonald et al, 2001). Interestingly, M1 receptors co-localize with NR1 on the dendrites and soma of hippocampal pyramidal neurons, and activation of M1 receptors potentiates NMDA receptor currents (Marino et al, 1998). Similar to previous reports (Sun and Alkon, 2005), our data might link postsynaptic cholinergic dysfunction with other substrates (PKC $\beta$ II and 
NMDA receptor) known to play essential roles in cognitive processes and provide further insight into the mechanisms by which impairment of M1-mediated signaling may underlie the cognitive decline of klotho mutant mice. Interestingly, mice lacking $\mathrm{PKC} \beta$ suffer from deficits in both cued and contextual fear conditioning (Weeber et al, 2000), which may be in line with our current results.

We observed here that McN facilitated LTP induction by activation of the JAK2/STAT3 signaling axis in klotho mutant mice. This suggests that NMDAR activation could be a mechanism for LTP facilitation through activation of the JAK2/STAT3 signaling axis by M1 mAChR. Reduced JAK2 activation in klotho mutant mice may result in impaired NMDAR function. As a consequence of NMDAR dysfunction, $\mathrm{Ca}^{2+}$ influx and extrusion across the plasma membrane, cytosolic buffering, and uptake into organelles, may be altered in neurons. Evidence showing that calcium influx is mediated by JAKs/STATs (Orellana et al, 2005) supports this notion. However, Nicolas et al (2012) showed that a JAK2 inhibitor, AG490, does not block the induction of NMDAR-dependent LTP. These results seem to contradict our observation that AG490 treatment blocked McNinduced recovery of NMDAR-dependent LTP. It suggests that JAK2/STAT3 activation differentially regulates synaptic plasticity and/or would be affected under klotho gene dysfunction.

In general, compensative upregulation of M1 receptors expressed on postsynaptic sites could occur if presynaptic ACh levels and ChAT levels decreased concomitantly with increased AChE expression. Unexpectedly, in our study, hippocampal M1 mAChR was downregulated in klotho mutant mice. Interestingly, Nomura et al (1997) demonstrated that SAMP8 also show decreased hippocampal M1 mAChR-binding activity. These findings raise the possibility that it may be difficult to induce compensatory adaptation in response to cholinergic neuronal dysfunction in models of aging, although this idea remains to be fully elucidated.

mAChRs undergo desensitization or downregulation in response to prolonged muscarinic agonist stimulation, resulting in a decline in $\mathrm{mAChR}$ density (Svedberg et al, 2004). However, $\mathrm{McN}$ treatment in the present experimental condition led to upregulated M1 mAChR in the hippocampus of klotho mutant mice. Functionally selective muscarinic agonists (ie, McN, oxotremorine, pilocarpine, and AF102B) antagonize the stimulatory effect of full agonist (ie, carbachol) on adenylate cyclase in cells expressing muscarinic M1 (Gurwitz et al, 1994). Thus, many of the functionally selective muscarinic receptor agonists seem to fall within the category of partial agonists (Hoyer and Boddeke, 1993). Bursa et al (1995) demonstrated that treatment of corticostriatal neurons with $\mathrm{McN}$ upregulates M1 mAChR mRNA in primary rat cortical neuronal cultures, suggesting that $\mathrm{McN}$ as a partial agonist could exert an antagonistic effect on this receptor transcript. Moreover, rapid and transient changes of striatal M1 mAChR mRNA levels are observed after the single administration of muscarinergic agents. For example, the full agonist carbachol dose-dependently upregulated M1 mAChR mRNA expression, while the antagonist trihexylphenidyl dose-dependently downregulated M1 mAChR mRNA expression (Chou et al, 1993), suggesting that short-term treatment with muscarinic agents positively regulates $\mathrm{M} 1 \mathrm{mAChR}$ mRNA expression in the early stage after treatment, contrary to negative regulation in the longterm treatment. Our results may be, at least in part, in line with earlier findings (Bursa et al, 1995; Chou et al, 1993). In addition, we cannot rule out the possibility that $\mathrm{McN}$ possesses other unknown pharmacological mechanisms, which are independent of M1 mAChR-like effects (Wang et al, 2008).

ERK1/2 family members were originally identified by their responsiveness to growth factor receptor tyrosine kinases. However, they are also activated by many G-protein-coupled receptors (GPCRs). One family of GPCRs that activates ERK in several systems is the mAChR family (M1-M5), although limited information is available regarding how $\mathrm{mAChR}$ activates ERK in the brain or the receptor subtype responsible. One important function of ERK activation relates to the localization of nuclear downstream targets, such as CREB (Sgambato et al, 1998). Although each mAChR subtype can activate ERK in cell culture, M1 significantly activates ERK in CA1 pyramidal neurons of the hippocampus (Berkeley et al, 2001).

It was reported (Pepitoni et al, 1997) that regulatory elements of the M1 mAChR gene located at the promoter region lack a CRE sequence (TGACGTCA), but contain an activator protein-1 (AP-1) binding element sequence (TGACTCA). Since CREB and AP-1 can form a heterodimer to activate the transcription of target genes (Shaulian and Karin, 2001), CREB phosphorylation may be related to M1 receptor stimulation, as shown in our $\mathrm{McN}$ effects.

BDNF expression may be coupled to CREB-mediated transcription. Interestingly, we observed that CREB protein levels were decreased in neurons in the cerebral cortex and hippocampus of aged rats (Chung et al, 2002). Asanuma et al (1996) indicated that CREB DNA-binding activity is decreased in several different brain regions of aged rats compared with young adult rats. We cannot rule out the possibility that reduced BDNF levels in klotho mutant mice are due to impaired CREB-mediated transcription of the BDNF gene.

Klotho mutant mice have impaired visual recognition memory and associative fear memory at 7 weeks of age, while the animals have normal memory function at 6 weeks of age (Nagai et al, 2003). Performance in the light-dark shuttle box and elevated-plus maze box tasks is normal in klotho mutant mice (Nagai et al, 2003). There is also no apparent difference in the nociceptive threshold to electric foot shock in the conditioned-fear task (Nagai et al, 2003), suggesting that there are no major changes in exploratory activity, emotionality, or shock sensitivity in klotho mutant mice. Therefore, it is possible that the impaired performance of mutant mice is mainly due to memory. In addition, we speculate that neuropathologic changes secondary by klotho gene deficiency can negatively affect homeostatic regulation in the M1 mAChR system and related cognitive network (see Supplementary Discussion for more details).

In conclusion, we propose that underlying mechanisms (Supplementary Figures S6 and S7) accountings for memory impairment in klotho mutant mice are as follows: (1) The JAK2/STAT3 axis not only upregulated ChAT expression but also sensitized M1 MAChR and increased 
NMDAR-mediated LTP in the hippocampus of wild-type mice. (2) Klotho gene deficiency resulted in inactivation of the JAK2/STAT3 axis, dysfunction of the cholinergic neuronal system and decreased NMDAR-mediated LTP.

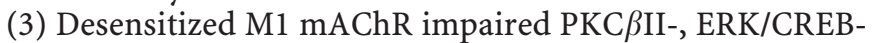
, and BDNF-dependent signaling. (4) McN, an M1 agonist, attenuated these impairments induced by klotho gene deficiency. Thus, it is possible that the klotho gene may be essential for maintaining cholinergic neuronal function in aging organisms, and that an M1 agonist may be useful in treating cognitive impairment associated with aging-related disorders.

\section{ACKNOWLEDGEMENTS}

This study was supported by a grant from the Brain Research Center from 21st Century Frontier Research Program (2012K001115) funded by the Ministry of Science and Technology, Republic of Korea. This work was, in part, supported by a Grant (\#20120006020) from the Bio \& Medical Technology Development Program through the National Research Foundation funded by the Ministry of Education, Science and Technology, Republic of Korea; by a Grant (\#E00025) of the Korea-Japan Joint Research Program, National Research Foundation of Korea, Republic of Korea; and by grants from Ministry of Health Labour and Welfare (MHLW): Research on Risk of Chemical Substances, and Ministry of Education, Culture, Sports, Science and Technology (MEST): Academic Frontier Project. Zhengyi Li and Jae-Hyung Bach were supported by BK 21 program. The English in this manuscript has been checked by at least two professional editors, both native speakers of English. For a certificate, please see: http://www.textcheck. com/certificate/x6dfJe

\section{DISCLOSURE}

The authors declare no conflict of interest.

\section{REFERENCES}

Alkam T, Nitta A, Furukawa-Hibi Y, Niwa M, Mizoguchi H, Yamada $\mathrm{K}$ et al (2010). Oral supplementation with Leu-Ile, a hydrophobic dipeptide, prevents the impairment of memory induced by amyloid beta in mice via restraining the hyperphosphorylation of extracellular signal-regulated kinase. Behav Brain Res 210: 184-190.

Anagnostaras SG, Murphy GG, Hamilton SE, Mitchell SL, Rahnama NP, Nathanson NM et al (2003). Selective cognitive dysfunction in acetylcholine M1 muscarinic receptor mutant mice. Nat Neurosci 6: 51-58.

Asanuma M, Nishibayashi S, Iwata E, Kondo Y, Nakanishi T, Vargas MG et al (1996). Alterations of cAMP response element-binding activity in the aged rat brain in response to administration of rolipram, a cAMP-specific phosphodiesterase inhibitor. Brain Res Mol Brain Res 41: 210-215.

Bach JH, Chung YH, Park SJ, Jin CH, Shin EJ, Jeong JH et al (2010). Klotho gene plays an important role in attenuating cognitive dysfunction in aging organism. Society for Neuroscience: San Diego, USA.

Berkeley JL, Gomeza J, Wess J, Hamilton SE, Nathanson NM, Levey AI (2001). M1 muscarinic acetylcholine receptors activate extracellular signal-regulated kinase in CA1 pyramidal neurons in mouse hippocampal slices. Mol Cell Neurosci 18: 512-524.

Bursa R, Gamalero SR, Genazzani E, Eva C (1995). In primary neuronal cultures muscarinic $\mathrm{m} 1$ and $\mathrm{m} 3$ receptor mRNA levels are regulated by agonists, partial agonists and antagonists. Eur J Pharmacol 289: 9-16.

Calabresi P, Centonze D, Gubellini P, Pisani A, Bernardi G (1998). Endogenous ACh enhances striatal NMDA-responses via M1-like muscarinic receptors and PKC activation. Eur J Neurosci 10: 2887-2895.

Cattaneo E, Conti L, De-Fraja C (1999). Signalling through the JAK-STAT pathway in the developing brain. Trends Neurosci 22: 365-369.

Chao LP, Wolfgram F (1972). Spectrophotometric assay for choline acetyltransferase. Anal Biochem 46: 114-118.

Chiba T, Yamada M, Sasabe J, Terashita K, Shimoda M, Matsuoka M et al (2009). Amyloid-beta causes memory impairment by disturbing the JAK2/STAT3 axis in hippocampal neurons. Mol Psychiatry 14: 206-222.

Chou H, Ogawa N, Asanuma M, Hirata H, Kondo Y, Mori A (1993). Rapid response of striatal muscarinic M1-receptor mRNA to muscarinic cholinergic agents in rat brain. Mol Brain Res 19: 211-214.

Chung YH, Kim EJ, Shin CM, Joo KM, Kim MJ, Woo HW et al (2002). Age-related changes in CREB binding protein immunoreactivity in the cerebral cortex and hippocampus of rats. Brain Res 956: 312-318.

De-Fraja C, Conti L, Magrassi L, Govoni S, Cattaneo E (1998). Members of the JAK/STAT proteins are expressed and regulated during development in the mammalian forebrain. J Neurosci Res 54: 320-330.

Fisher A, Pittel Z, Haring R, Bar-Ner N, Kliger-Spatz M, Natan N et al (2003). M1 muscarinic agonists can modulate some of the hallmarks in Alzheimer's disease: implications in future therapy. J Mol Neurosci 20: 349-356.

Franklin KBJ, Paxinos G (2008). The Mouse Brain in Stereotaxic Coordinates. 3rd edn. Academic Press: San Diego, CA.

Gurwitz D, Haring R, Haring R, Heldman E, Fraser CM, Manor D et al (1994). Duscrete activation of transduction pathways associated with acetylcholine $\mathrm{m} 1$ receptor by several muscarinic ligands. Eur J Pharmacol 267: 21-31.

Hoyer D, Boddeke HW (1993). Partial agonists, full agonists, antagonists: dilemmas of definition. Trends Pharmacol Sci 14: $270-275$.

Ihle JN, Witthuhn BA, Quelle FW, Yamamoto K, Silvennoinen O (1995). Signaling through the hematopoietic cytokine receptors. Annu Rev Immunol 13: 369-398.

Jin CH, Shin EJ, Park JB, Jang CG, Li Z, Kim MS et al (2009). Fustin flavonoid attenuates beta-amyloid (1-42)-induced learning impairment. J Neurosci Res 87: 3658-3670.

Kuro-o M, Matsumura Y, Aizawa H, Kawaguchi H, Suga T, Utsugi T et al (1997). Mutation of the mouse klotho gene leads to a syndrome resembling ageing. Nature 390: 45-51.

Kurosu H, Yamamoto M, Clark JD, Pastor JV, Nandi A, Gurnani P et al (2005). Suppression of aging in mice by the hormone Klotho. Science 309: 1829-1833.

Li SA, Watanabe M, Yamada H, Nagai A, Kinuta M, Takei K (2004). Immunohistochemical localization of Klotho protein in brain, kidney, and reproductive organs of mice. Cell Struct Funct 29: 91-99.

Liu N, Varma S, Shooter EM, Tolwani RJ (2005). Enhancement of Schwann cell myelin formation by K252a in the Trembler-J mouse dorsal root ganglion explant culture. J Neurosci Res 79: 310-317.

Lu WY, Xiong ZG, Lei S, Orser BA, Dudek E, Browning MD et al (1999). G-protein-coupled receptors act via protein kinase $C$ and Src to regulate NMDA receptors. Nat Neurosci 2: 331-338. 
MacDonald JF, Kotecha SA, Lu WY, Jackson MF (2001). Convergence of PKC-dependent kinase signal cascades on NMDA receptors. Curr Drug Targets 2: 299-312.

Marino MJ, Rouse ST, Levey AI, Potter LT, Conn PJ (1998). Activation of the genetically defined $\mathrm{ml}$ muscarinic receptor potentiates $\mathrm{N}$-methyl-D-aspartate (NMDA) receptor currents in hippocampal pyramidal cells. Proc Natl Acad Sci USA 95: 11465-11470.

Mehler MF, Kessler JA (1997). Hematolymphopoietic and inflammatory cytokines in neural development. Trends Neurosci 20: 357-365.

Min SS, Quan HY, Ma J, Han JS, Jeon BH, Seol GH (2009). Chronic brain inflammation impairs two forms of long-term potentiation in the rat hippocampal CA1 area. Neurosci Letters 456: 20-24.

Mizuno M, Yamada K, Takei N, Tran MH, He J, Nakajima A et al (2003). Phosphatidylinositol 3-kinase: a molecule mediating BDNF-dependent spatial memory formation. Mol Psychiatry 8: 217-224.

Nagai T, Yamada K, Kim HC, Kim YS, Noda Y, Imura A et al (2003). Cognition impairment in the genetic model of aging klotho gene mutant mice: a role of oxidative stress. FASEB J 17: 50-52.

Nicolas CS, Peineau S, Amici M, Csaba Z, Fafouri A, Javalet C et al (2012). The Jak/STAT pathway is involved in synaptic plasticity. Neuron 73: 374-390.

Nomura Y, Kitamura Y, Ohnuki T, Arima T, Yamanaka Y, Sasaki K et al (1997). Alterations in acetylcholine, NMDA, benzodiazepine receptors and protein kinase $\mathrm{C}$ in the brain of the senescenceaccelerated mouse: an animal model useful for studies on cognitive enhancers. Behav Brain Res 83: 51-55.

O'Neil C, Marcusson J, Nordberg A, Winblad B (1987). The influence of age on neurotransmitters in the human brain. In: Govoni SBattaini F (eds) NATO Advanced Research Workshop on Modifications of Cell to Cell Signals during Normal and Pathological Aging. Springer-Verlag: Salò, Garda Lake, Italy. Vol 9, pp 183-198.

Orellana DI, Quintanilla RA, Gonzalez-Billault C, Maccioni RB (2005). Role of the JAKs/STATs pathway in the intracellular calcium changes induced by interleukin- 6 in hippocampal neurons. Neurotox Res 8: 295-304.

Pepitoni S, Wood IC, Buckley NJ (1997). Structure of the m1 muscarinic acetylcholine receptor gene and its promoter. J Biol Chem 272: 17112-17117.

Sgambato V, Vanhoutte P, Pages C, Rogard M, Hipskind R, Besson MJ et al (1998). In vivo expression and regulation of Elk-1, a target of the extracellular-regulated kinase signaling pathway, in the adult rat brain. J Neuroscience 18: 214-226.
Shaulian E, Karin M (2001). AP-1 in cell proliferation and survival. Oncogene 20: 2390-2400.

Shin EJ, Chae JS, Park SJ, Kim SC, Koo KH, Yamada K et al (2009). Growth hormone-releaser diet attenuates beta-amyloid(1-42)induced cognitive impairment via stimulation of the insulin-like growth factor (IGF)-1 receptor in mice. J Pharmacol Sci 109: 139-143.

Sun MK, Alkon DL (2005). Protein kinase C isozymes: memory therapeutic potential. Curr Drug Targets CNS Neurol Disord 4: 541-552.

Svedberg MM, Bednar I, Nordberg A (2004). Effect of subchronic galantamine treatment on neuronal nicotinic and muscarinic receptor subtypes in transgenic mice overexpressing human acetylcholinesterase. Neuropharmacology 47: 558-571.

Wall PM, Flinn J, Messier C (2001). Infralimbic muscarinic M1 receptors modulate anxiety-like behaviour and spontaneous working memory in mice. Psychopharmacology (Berl) 155: $58-68$.

Walland A, Pieper MP (1998). Central activation of the sympathetic nervous system including the adrenals in anaesthetized guinea pigs by the muscarinic agonist talsaclidine. NaunynSchmiedeberg's Arch Pharmacol 357: 426-430.

Wang Q, Zengin A, Ying W, Newell KA, Wang P, Yeo W et al (2008). Chronic treatment with simvastatin upregulates muscarinic M1/4 receptor binding in the rat brain. Neuroscience 154: $1100-1106$.

Wayman GA, Impey S, Marks D, Saneyoshi T, Grant WF, Derkach V et al (2006). Activity-dependent dendritic arborization mediated by CaM-kinase I activation and enhanced CREBdependent transcription of Wnt-2. Neuron 50: 897-909.

Weeber EJ, Atkins CM, Selcher JC, Varga AW, Mirnikjoo B, Paylor $\mathrm{R}$ et al (2000). A role for the beta isoform of protein kinase $\mathrm{C}$ in fear conditioning. J Neurosci 20: 5906-5914.

Williams CM, El Mohsen MA, Vauzour D, Rendeiro C, Butler LT, Ellis JA et al (2008). Blueberry-induced changes in spatial working memory correlate with changes in hippocampal CREB phosphorylation and brain-derived neurotrophic factor (BDNF) levels. Free Radic Biol Med 45: 295-305.

Zhang LC, Buccafusco JJ (2000). Adaptive changes in M1 muscarinic receptors localized to specific rostral brain regions during and after morphine withdrawal. Neuropharmacology 39: 1720-1731.

Zola-Morgan S, Squire LR, Amaral DG (1986). Human amnesia and the medial temporal region: enduring memory impairment following a bilateral lesion limited to field CA1 of the hippocampus. J Neurosci 6: 2950-2967.

Supplementary Information accompanies the paper on the Neuropsychopharmacology website (http://www.nature.com/npp) 